\title{
Electrochemical Sensor for Simultaneous Determination of Theophylline and Caffeine Based on a Novel poly(folic acid)/graphene Composite Film Modified Electrode
}

\author{
Xiaoli Shu, Feng Bian, Qianqian Wang, Xiaofei Qin, Yan Wang ${ }^{*}$ \\ College of Chemistry, Chemical Engineering and Materials Science, Collaborative Innovation Center \\ of Functionalized Probes for Chemical Imaging in Universities of Shandong, Shandong Normal \\ University, Jinan 250014, P. R. China \\ *E-mail: fagong@sdu.edu.cn
}

doi: $10.20964 / 2017.05 .37$

Received: 30 January 2017 / Accepted: 8 March 2017 / Published: 12 April 2017

In this work, a novel poly(folic acid)/ graphene composite film modified electrode was developed to construct an electrochemical sensor for simultaneous determination of theophylline (TP) and caffeine (CAF). The fabrication and characterization of nanocomposite film were investigated in details by electrochemistry and scanning electron microscopy. This new electrochemical sensor displayed superior electrocatalytic property to the oxidation of TP and CAF, which obviously improved the sensitive detection of the two compounds in the terms of high sensitivity and wide linear range. Under the optimized experimental conditions, the detection limits were obtained to be $0.03 \mu \mathrm{mol} \mathrm{L}^{-1}$ for TP and $0.08 \mu \mathrm{mol} \mathrm{L}^{-1}$ for CAF, respectively. The novel sensor was successfully used for the simultaneous detection of TP and CAF in food samples.

Keywords: Folic acid; Graphene; Chemically modified electrode; Theophylline; Caffeine

\section{FULL TEXT}

(C) 2017 The Authors. Published by ESG (www.electrochemsci.org). This article is an open access article distributed under the terms and conditions of the Creative Commons Attribution license (http://creativecommons.org/licenses/by/4.0/). 